\title{
Cellulose crystallinity index: measurement techniques and their impact on interpreting cellulase performance
}

\author{
Sunkyu Park1,3, John O Baker1, Michael E Himmel', Philip A Parilla² and David K Johnson*1
}

\begin{abstract}
Although measurements of crystallinity index (CI) have a long history, it has been found that $\mathrm{Cl}$ varies significantly depending on the choice of measurement method. In this study, four different techniques incorporating X-ray diffraction and solid-state ${ }^{13} \mathrm{C}$ nuclear magnetic resonance (NMR) were compared using eight different cellulose preparations. We found that the simplest method, which is also the most widely used, and which involves measurement of just two heights in the X-ray diffractogram, produced significantly higher crystallinity values than did the other methods. Data in the literature for the cellulose preparation used (Avicel PH-101) support this observation. We believe that the alternative X-ray diffraction (XRD) and NMR methods presented here, which consider the contributions from amorphous and crystalline cellulose to the entire XRD and NMR spectra, provide a more accurate measure of the crystallinity of cellulose. Although celluloses having a high amorphous content are usually more easily digested by enzymes, it is unclear, based on studies published in the literature, whether $\mathrm{Cl}$ actually provides a clear indication of the digestibility of a cellulose sample. Cellulose accessibility should be affected by crystallinity, but is also likely to be affected by several other parameters, such as lignin/hemicellulose contents and distribution, porosity, and particle size. Given the methodological dependency of cellulose $\mathrm{Cl}$ values and the complex nature of cellulase interactions with amorphous and crystalline celluloses, we caution against trying to correlate relatively small changes in $\mathrm{Cl}$ with changes in cellulose digestibility. In addition, the prediction of cellulase performance based on low levels of cellulose conversion may not include sufficient digestion of the crystalline component to be meaningful.
\end{abstract}

\section{Background}

Cellulose is a high molecular weight linear polymer composed of D-glucopyranose units linked by $\beta$-1,4-glycosidic bonds. The repeating unit of cellulose is cellobiose. Hydroxyl groups present in cellulose macromolecules are involved in a number of intra- and intermolecular hydrogen bonds, which result in various ordered crystalline arrangements. Four different crystalline allomorphs have been identified by their characteristic X-ray diffraction (XRD) patterns and solid-state ${ }^{13} \mathrm{C}$ nuclear magnetic resonance (NMR) spectra: celluloses I, II, III and IV. Cellulose I is the most abundant form found in nature. Cellulose II can be prepared by two distinct routes: mercerization (alkali treatment) and regeneration (solubiliza-

* Correspondence: david.johnson@nrel.gov

${ }^{1}$ Biosciences Center, National Renewable Energy Laboratory, 1617 Cole Blvd, Golden, CO 80401, USA

Full list of author information is available at the end of the article tion and subsequent recrystallization). Celluloses $\mathrm{III}_{\mathrm{I}}$ and $\mathrm{III}_{\mathrm{II}}$ can be formed from celluloses I and II, respectively, by treatment with liquid ammonia, and the reaction is reversible [1]. Celluloses $\mathrm{IV}_{\mathrm{I}}$ and $\mathrm{IV}_{\mathrm{II}}$ can be obtained by heating celluloses $\mathrm{III}_{\mathrm{I}}$ and $\mathrm{III}_{\mathrm{II}}$, respectively [2]. Thorough reviews of cellulose crystalline allomorphs can be found elsewhere [3-5].

The crystalline structure of cellulose has been studied since its discovery in the 19th century. Currently, cellulose I is receiving increased attention due to its potential use in bioenergy production. The crystalline structure of cellulose was first established by Carl von Nägeli in 1858 [6], and the result was later verified by X-ray crystallography [7]. Several different models of cellulose I have been proposed since then; however, its structure is still not fully understood because of its complexity. It is known that the crystalline structure of cellulose I is a mixture of two distinct crystalline forms: celluloses $I_{\alpha}$ (triclinic) and 
$\mathrm{I}_{\beta}$ (monoclinic), which were verified using solid-state ${ }^{13} \mathrm{C}$ NMR [8]. The relative amounts of celluloses $\mathrm{I}_{\alpha}$ and $\mathrm{I}_{\beta}$ vary with the source of the cellulose, with the $I_{\beta}$ form being dominant in higher plants. The size of cellulose crystallites is small, generally about $5 \mathrm{~nm}$ in width, thus the resolution of the XRD pattern is not sufficient to extract exact information about crystal lattices within the structure. Cellulose crystallites are thought to be imperfect, and thus a significant portion of the cellulose structure is less ordered; this portion is often referred to as amorphous. A parameter termed the crystallinity index (CI) has been used to describe the relative amount of crystalline material in cellulose. The traditional two-phase cellulose model describes cellulose chains as containing both crystalline (ordered) and amorphous (less ordered) regions [9].

The CI of celluloses have been measured using several different techniques including XRD, solid-state ${ }^{13} \mathrm{C}$ NMR, infrared (IR) spectroscopy and Raman spectroscopy. There have also been several methods used for calculating $\mathrm{CI}$ from the raw spectrographic data, particularly for XRD. Methods using Fourier transform (FT)-IR spectroscopy determine CI by measuring relative peak heights or areas [10-12]. The determination of CI using FT-IR spectroscopy is the simplest method, but gives only relative values, because the spectrum always contains contributions from both crystalline and amorphous regions. In many studies, the CI calculated from an FT-IR spectrum is compared with those from XRD and/or NMR measurements. Because the FT-IR method is not an absolute measurement technique, we chose not to use it in this study. Raman spectroscopy has also been employed to determine CI [13].

The CI of cellulose has been used for more than five decades to interpret changes in cellulose structure after physicochemical and biological treatments. However, it has been found that the CI varies significantly, depending on the choice of measurement method $[11,14,15]$. Thygesen and co-workers compared four different analysis techniques involving XRD, and reported that the CI of Avicel cellulose varied significantly from $39 \%$ to $67 \%$, depending on the technique used [15].

In this study, we made critical comparisons between the different techniques using XRD and solid-state ${ }^{13} \mathrm{C}$ NMR. Comparisons were made with literature data for the CI of one type of cellulose (Avicel PH-101) using these methods. In addition, we measured the CI of eight celluloses from different sources to demonstrate the dissimilarity in results that can be obtained using different methods. The effect of interpreting cellulose enzymatic digestibility in terms of the crystallinities determined by the different techniques is also discussed.

\section{Materials and methods Cellulose samples}

Eight high purity $(>95 \%$ cellulose in all cases except for Solka-Floc, which was $>93 \%$ ) celluloses were used in this study. Bacterial microcrystalline cellulose (BMCC) was prepared from Gluconacetobacter hansenii (American Type Culture Collection (ATCC) 10821) in our laboratory [16]. The seven other celluloses were commercially available: Sigmacell 50 (S5504), Sigmacell 20 (S3504), Avicel PH-101 (11365), Fluka cellulose (22183), $\alpha$-cellulose (C8002) (all purchased from Sigma-Aldrich, St. Louis, MO, USA), Solka-Floc (International Fiber Corporation (North Tonawanda, NY, USA) and JT Baker cellulose (1529) (Mallinckrodt Baker, Phillipsburg, NJ, USA). Ball milled cellulose was prepared by milling Avicel PH-101 $(1.5 \mathrm{~g})$ for 20 minutes in a cryogenic impact mill $(6770$ Freezer Mill; Spex, Metuchen, NJ, USA) cooled by liquid nitrogen.

\section{$\mathrm{Cl}$ of celluloses}

The CI of the eight celluloses was measured by two different techniques: XRD and solid-state ${ }^{13} \mathrm{C}$ NMR. XRD was performed on a four-circle goniometer (XDS-2000 Polycrystalline Texture Stress (PTS) goniometer; Scintag, Scintag Inc., Cupertino, CA, USA) using $\mathrm{CuK} \alpha$ radiation generated at $45 \mathrm{kV}$ and $36 \mathrm{~mA}$. The $\mathrm{CuK \alpha}$ radiation consists of $\mathrm{K} \alpha 1(0.15406 \mathrm{~nm})$ and $\mathrm{K} \alpha 2(0.15444 \mathrm{~nm})$ components, and the resultant XRD data has both components present; the $\mathrm{CuK} \alpha$ radiation is filtered out from the data using a single-channel analyzer on the output from the semiconductor detector, and does not contribute to the data. The source slits were $2.0 \mathrm{~mm}$ and $4.0 \mathrm{~mm}$ at a 290 $\mathrm{mm}$ goniometer radius, and the detector slits were 1.0 $\mathrm{mm}$ and $0.5 \mathrm{~mm}$ at the same radius. Dried cellulose samples (approximately $0.5 \mathrm{~g}$ ) were mounted onto a quartz substrate using several drops of diluted glue. This diluted glue is amorphous when it is dry, and adds almost no background signal (lower line in Figure 1a). Scans were obtained from 5 to 50 degrees $2 \theta$ in 0.05 degree steps for 15 seconds per step.

To calculate the CI of cellulose from the XRD spectra, three different methods were used. First, CI was calculated from the height ratio between the intensity of the crystalline peak $\left(\mathrm{I}_{002}-\mathrm{I}_{\mathrm{AM}}\right)$ and total intensity $\left(\mathrm{I}_{002}\right)$ after subtraction of the background signal measured without cellulose [17-19] (Figure 1a). Second, individual crystalline peaks were extracted by a curve-fitting process from the diffraction intensity profiles [20,21]. A peak fitting program (PeakFit; www.systat.com) was used, assuming Gaussian functions for each peak and a broad peak at around $21.5^{\circ}$ assigned to the amorphous contribution (Figure 1b). Iterations were repeated until the maximum $\mathrm{F}$ number was obtained. In all cases, the $\mathrm{F}$ number was 

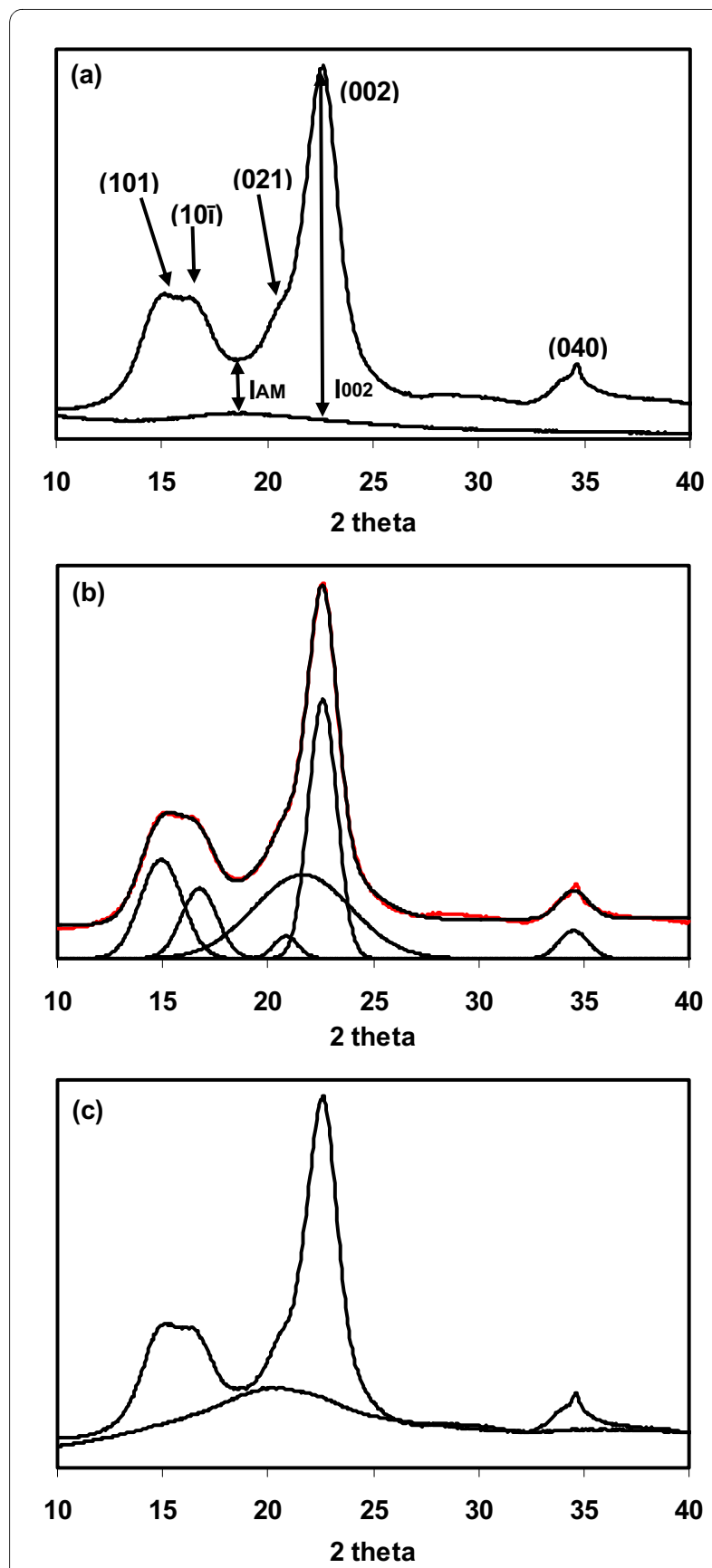

Figure $1 \mathrm{X}$-ray diffraction spectra of Avicel PH-101 illustrating the three most common methods for calculating $\mathrm{Cl}$. (a) Peak height method, (b) peak deconvolution method and (c) amorphous subtraction method. The XRD data were collected using CuKa radiation.

$>10,000$, which corresponds to a $R^{2}$ value of 0.997 . Third, ball-milled cellulose (Figure 2c) was used as amorphous cellulose to subtract the amorphous portion from the diffraction profiles [15] (Figure 1c). After subtracting the diffractogram of the amorphous cellulose from the diffractogram of the whole sample, the CI was calculated by

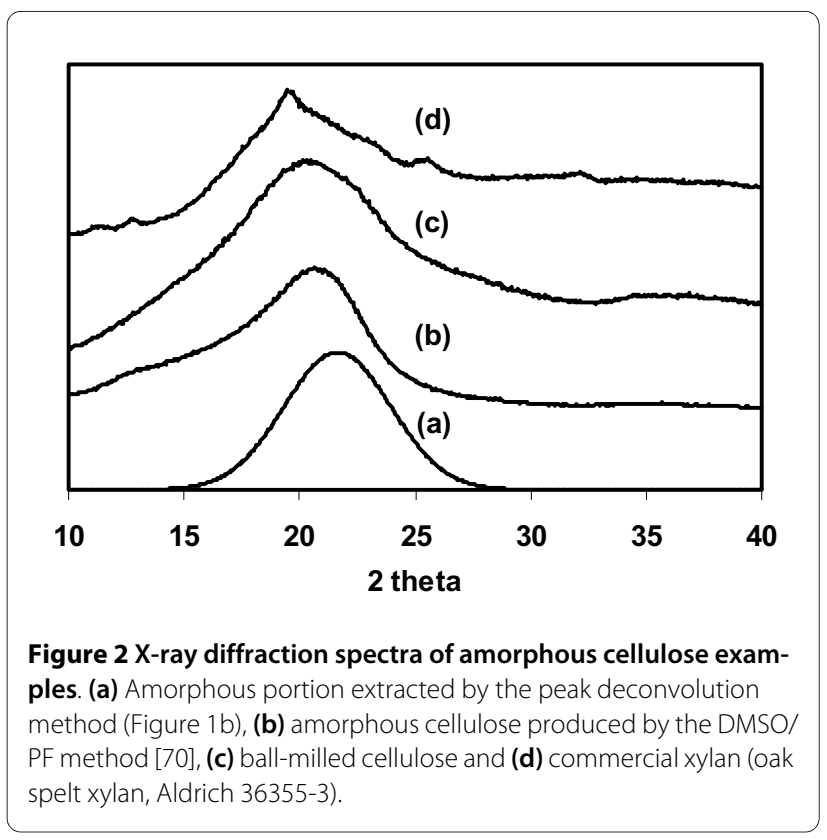

dividing the remaining diffractogram area due to crystalline cellulose by the total area of the original diffractogram.

Solid-state ${ }^{13} \mathrm{C}$ NMR spectra were collected at $4.7 \mathrm{~T}$ with cross-polarization and magic angle spinning (MAS) in a $200 \mathrm{MHz}$ spectrometer (Avance; Bruker, Madison, WI, USA). Variable amplitude cross-polarization was used to minimize intensity variations of the non-protonated aromatic carbons that are sensitive to HartmannHahn mismatch at higher MAS rotation rates [22]. The ${ }^{1} \mathrm{H}$ and ${ }^{13} \mathrm{C}$ fields were matched at $53.6 \mathrm{kHz}$, and a $1 \mathrm{~dB}$ ramp was applied to the proton rotating-frame during the matching period. Acquisition time was 0.051 seconds, and sweep-width was $20 \mathrm{kHz}$. MAS was performed at $6500 \mathrm{~Hz}$. The number of scans was 10,000 to 20,000 with a relaxation time of 1.0 seconds. The CI was determined by separating the $\mathrm{C} 4$ region of the spectrum into crystalline and amorphous peaks, and calculated by dividing the area of the crystalline peak ( 87 to $93 \mathrm{ppm}$ ) by the total area assigned to the C4 peak ( 80 to $93 \mathrm{ppm}$ ) [23] (Figure $3 a$, Figure $3 b)$.

\section{Results and discussion}

XRD and solid-state ${ }^{13} \mathrm{C}$ NMR have most widely been used to evaluate the CI of cellulose and the spectral analysis techniques that have been used are summarized here. Figure 1a shows the XRD spectrum of Avicel PH-101, with the peaks labeled to indicate their crystal lattice assignments, assuming the $I_{\beta}$ phase is aligned with the fiber axis along the $b$ direction [24]. Figure 3a shows the solid-state ${ }^{13} \mathrm{C}$ NMR spectrum of Avicel PH-101; the labels show which peaks have been assigned to the differ- 

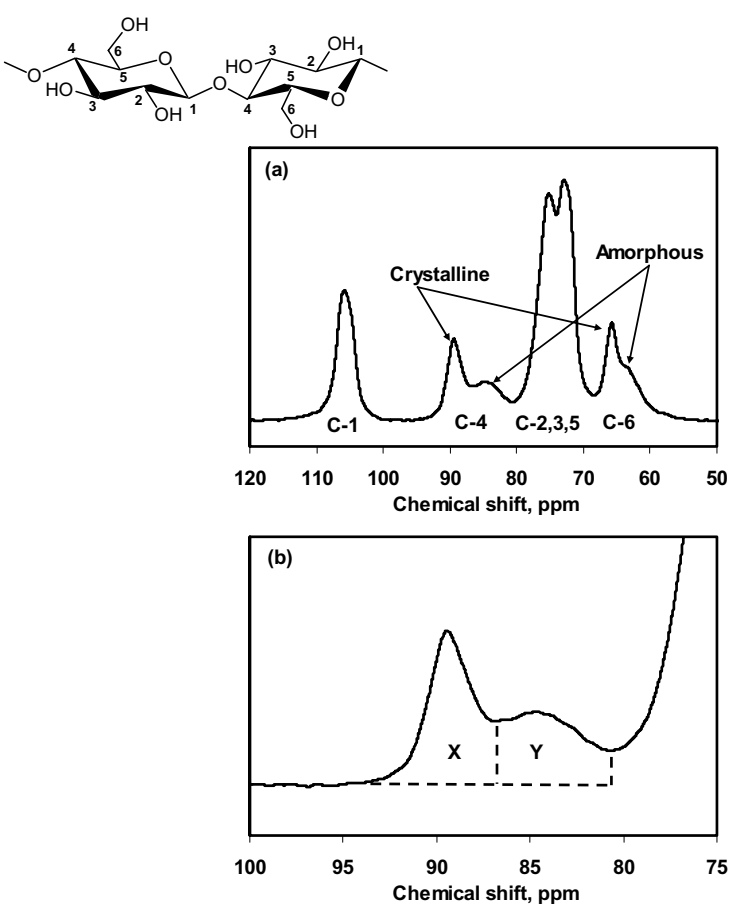

Figure 3 Solid state ${ }^{13}$ C NMR spectrum of Avicel PH-101. (a) Whole spectrum showing the assignment of peaks to the carbons in a glucopyranose repeat unit and (b) sub-spectrum showing peaks assigned to the $\mathrm{C} 4$ in cellulose. The $\mathrm{Cl}$ is calculated by $x /(x+y)$.

ent carbon atoms of the glucopyranose repeating units in cellulose, and which peaks have been attributed to the carbon atoms in crystalline and amorphous cellulose.

For the XRD methods, one important factor to consider is the preferred orientation of the crystallites (also known as texture). Often the manner in which samples are synthesized, the nature of the crystallites and the method of sample preparation for XRD causes the development of texture in the sample. It is well known that this will drastically influence the relative intensities of the diffraction peaks and will correspondingly influence the CI. How much this influence extends depends on the exact definition of the CI. The best suggestion to avoid a texturebiased CI is to carefully prepare samples to eliminate or minimize texture [15].

In its present state, measurement of cellulose CI by XRD provides a qualitative or semi-quantitative evaluation of the amounts of amorphous and crystalline cellulosic components in a sample. Development of a truly quantitative cellulose $\mathrm{CI}$ is laudable, but would need to proceed along the principles established for quantitative XRD phase analysis. $[25,26]$. The greatest barrier to this goal is the lack of appropriate cellulose standards needed to calibrate the measurement. Most current cellulose CI definitions do not follow such principles.

\section{Method 1: the XRD peak height method}

This method, developed by Segal and coworkers [19], examined the changes in XRD spectra during decrystallization of cotton cellulose by chemical and mechanical methods. The proposed method was for empirical measurements to allow rapid comparison of cellulose samples. CI was calculated from the ratio of the height of the 002 peak $\left(\mathrm{I}_{002}\right)$ and the height of the minimum $\left(\mathrm{I}_{\mathrm{AM}}\right)$ between the 002 and the 101 peaks, as shown in Figure 1a. This method is useful for comparing the relative differences between samples; however, we suggest that it should not be used as a method for estimating the amount of crystalline and amorphous material in a cellulose sample for the following reasons.

1. The minimum position between the 002 and the 101 peaks $\left(\mathrm{I}_{\mathrm{AM}}\right.$ which is at about $18.3^{\circ}$ in Figure 1a) is not aligned with the maximum height of the amorphous peak. The apex of the peak that is due to amorphous cellulose is likely to be higher than $18.3^{\circ}$. As shown in Figure 2, the apex of the peak of regenerated amorphous cellulose (2b) was found to be at $20.7^{\circ}$, ball milled cellulose (2c) was at $20.5^{\circ}$ and commercial xylan (2d) was at $19.5^{\circ}$. From the peak deconvolution method, the amorphous peak (2a) was predicted to be at around $21.5^{\circ}$. Thus, the $\mathrm{I}_{\mathrm{AM}}$ value for the height method is significantly underestimated, resulting in an overestimation of the CI.

2. There are at least four crystalline peaks, but only the highest peak (002) is used in the calculation. This excludes contributions from the other crystalline peaks, putting too much emphasis on the contribution from one alignment of the cellulose crystal lattice.

3. Peaks in the cellulose diffraction spectrum are very broad and vary considerably in their width. A simple height comparison cannot be expected to provide a reasonable estimate of cellulose crystallinity, as it neglects variation in peak width, which can also be affected by crystallite size [21].

We believe that for these reasons the relative height to the minimum can only be taken as a rough approximation of the contribution of amorphous cellulose to the cellulose diffraction spectrum.

\section{Method 2: the XRD deconvolution method}

This method requires software to separate amorphous and crystalline contributions to the diffraction spectrum using a curve-fitting process. For the curve fitting, a few assumptions have to be made, such as the shape and number of peaks. Gaussian [20,27], Lorentzian [14] and Voigt [21] functions are commonly used for deconvolution of XRD spectra. Five crystalline peaks (101, 10ī, 021, 002 and 040 ) have been separated in many cases [20,21], 
but four crystalline peaks (101, 10ī, 002 and 040) have been assumed in other studies [14]. Figure $1 \mathrm{~b}$ shows the deconvolution of Avicel PH-101 using five Gaussian crystalline peaks. CI is calculated from the ratio of the area of all crystalline peaks to the total area.

An important assumption for this analysis is that increased amorphous contribution is the main contributor to peak broadening. However, in addition to crystalline disorder (amorphous content), there are other intrinsic factors that influence peak broadening, such as crystallite size and non-uniform strain within the crystal. It might be possible to deconvolute these contributions with well-behaved samples that can be resolved into many narrow diffraction peaks over a significant range of $2 \theta$. Unfortunately, cellulose peaks are very broad and not well resolved, with overlapping peaks. It is generally accepted in the cellulose community that peak broadening is due to the amorphous cellulose. However, crystallite size is an equally important issue for peak broadening and some studies have assumed that the latter was the main contributor [21]. Information about average crystallite size has been calculated from this method using the Scherrer formula. The width of the crystalline peak (002) at half height has been directly related to crystallite size and calculated to be about 4 to $7 \mathrm{~nm}$ in most references $[14,17,21,28]$.

\section{Method 3: the XRD amorphous subtraction method}

The basis for this method was outlined by Ruland [29], who determined crystallinity by subtracting the amorphous contribution from diffraction spectra using an amorphous standard. The challenge is to select an amorphous standard that is similar to the amorphous component in the sample. Various materials have been used as an amorphous standard, such as ball-milled cellulose, regenerated cellulose, and xylan or lignin powder. A scale factor is applied to the spectrum of the amorphous material so that after subtraction of the amorphous spectrum from the original spectrum, no part of the residual spectrum contains a negative signal. Figure 1c shows how an amorphous spectrum has been scaled to just touch the diffraction spectrum to give the resulting subtracted spectrum that is due to the crystalline cellulose present in the sample. CI is calculated as the ratio between the area of the crystalline contribution and the total area.

\section{Method 4: the NMR C4 peak separation method}

We have used solid-state ${ }^{13} \mathrm{C}$ NMR to evaluate the CI of cellulose samples, employing the method of Newman [23]. In the NMR spectra in Figure 3, the peak at $89 \mathrm{ppm}$ is assigned to the $\mathrm{C} 4$ carbon in ordered cellulose structures, and the peak at $84 \mathrm{ppm}$ is assigned to the $\mathrm{C} 4$ carbon of disordered cellulose [30]. CI is calculated by dividing the area of the crystalline peak (integrating the peak from 87 to $93 \mathrm{ppm}$ ) by the total area assigned to the $\mathrm{C} 4$ peaks (integrating the region from 80 to $93 \mathrm{ppm}$ ). This approach has been used by others assessing the influence of cellulose crystallinity on cellulose digestibility [31].

This method was chosen over a more detailed analysis of the C4 peaks using peak deconvolution software because it was our goal is to determine the effect of CI on the digestibility of biomass derived celluloses, which have a relatively low order. As noted by Larsson [32], the lack of spectral detail in celluloses of low order make detailed analysis impossible. Peak deconvolution methods have been applied to more ordered celluloses [32]. The shape and number of peaks were selected so that they agreed with the mixed or composite crystal model of Atalla and VanderHart [8]. Lorentzian [33] and Gaussian [34-36] functions were used to perform the deconvolution of the C4 peaks. In some studies [37,38], a combination of Lorentzian and Gaussian functions was used to fit the $\mathrm{C} 4$ region (80 to $93 \mathrm{ppm}$ ) with seven peaks that range in full width at half height from 70 to more than $500 \mathrm{~Hz}$. Compared with the detailed peak deconvolution methods, the Newman method incorporates the two peaks previously assigned to the fibril surface and the majority of the broad peak assigned to amorphous cellulose into the peak for disordered cellulose at $84 \mathrm{ppm}$. The peak assigned to more ordered cellulose structures $(89 \mathrm{ppm})$ includes those peaks previously assigned to the $\mathrm{I}_{\alpha}, \mathrm{I}_{\beta}$ and paracrystalline cellulose components.

\section{Frequencies of methods and variations in the $\mathrm{Cl}$ of Avicel PH-101}

Based on a literature survey of about 80 journal articles that reported the $\mathrm{CI}$ for commercially available celluloses, the XRD peak height method is the most widely used to determine CI, being used in about 70 to $85 \%$ of the studies (Table 1). It seems likely that the popularity of this method results from its ease of use. The other methods were each used in 5 to $10 \%$ of the references found in this study. The XRD peak deconvolution method is widely used to analyze cellulose II structure, for example, in cellulose film and lyocell, because the XRD peak height method cannot be applied to the cellulose II allomorph. A typical X-ray diffraction profile of cellulose II can be found elsewhere [39].

Figure 4 shows the literature values for the $\mathrm{CI}$ of Avicel PH-101 categorized by the different measurement techniques, and it is obvious that the CI of cellulose measured by different methods produces different results. Avicel PH-101 was chosen because it was the most widely measured cellulose reported in the literature. We made the assumption that all Avicel PH-101 used in the literature was of the same quality, even though it has been reported that the quality of Avicel $\mathrm{PH}-101$ can vary between batches and production locations $[40,41]$. 
Table 1: Frequencies of different methods reported in the literature for measuring the crystallinity index of commercial celluloses.

\begin{tabular}{llc}
\hline Instrument & Analysis technique & Frequency, \% \\
\hline XRD & Peak height & 70 to 85 \\
\hline & Peak deconvolution & 5 to 10 \\
& & \\
\hline & Amorphous subtraction & 5 to 10 \\
\hline NMR & C4 peak separation & 5 to 10 \\
\hline $\begin{array}{l}\text { NMR, nuclear magnetic resonance; XRD, X-ray diffraction. } \\
\text { About } 80 \text { articles (30 for Avicel PH-101 and } 50 \text { for other commercial } \\
\text { celluloses) were analyzed in this study. }\end{array}$
\end{tabular}

The values plotted in Figure 4 were reported by several research groups (XRD peak height method [42-50], XRD deconvolution method [27,51], XRD amorphous subtraction method $[40,52,53]$ and NMR C4 peak separation method $[13,27,54])$. The filled diamonds in Figure 4 are the values we obtained using the various techniques.

\section{$\mathrm{Cl}$ of commercial celluloses}

To demonstrate the differences in $\mathrm{CI}$ measured by different methods, eight cellulose samples were tested (Table 2). The BMCC sample gave the highest $\mathrm{CI}$, and $\alpha$-cellulose the lowest. Although the methods give different $\mathrm{CI}$ results for a given cellulose, the order of crystallinity for these celluloses is relatively consistent within each measurement technique. These results again show that the XRD peak height method produces a higher $\mathrm{CI}$ than the other methods. We found the value for Avicel PH-101 to

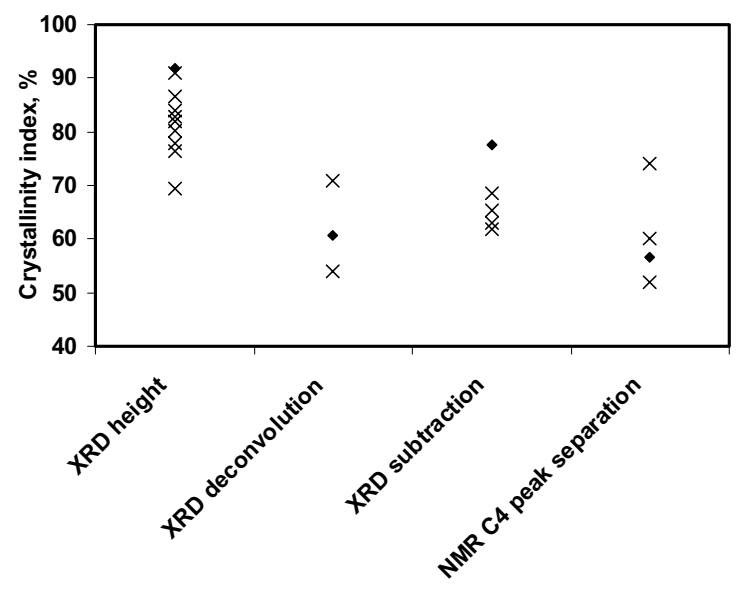

Figure $4 \mathrm{Cl}$ of Avicel $\mathrm{PH}-101$ from the literature in terms of measurement techniques. Crosses indicate literature values and black diamonds indicate the values obtained by the authors. be $91.7 \%$ using the XRD peak height method after baseline subtraction of the spectrum. Some of the reference values in Figure 4 were calculated without considering the baseline; our value would be $81.0 \%$ if calculated without baseline subtraction.

Generally, the different methods produce CI values in the following order: XRD height method $>$ XRD amorphous subtraction $>$ XRD peak deconvolution $>$ NMR C4 peak separation. The important question is which method provides the most accurate evaluation of cellulose crystallinity. Because of the limitations and problems mentioned earlier, there is no simple answer. In addition, the structure of cellulose is still not fully understood and the assumption that cellulose has only two regions, crystalline and amorphous, might be not realistic. Some researchers have suggested that there is a paracrystalline region in cellulose, which is less ordered with a somewhat larger mobility than the crystalline cellulose structure [32].

\section{Interpretation of enzymatic hydrolysis of cellulose in terms of cellulose $\mathrm{Cl}$}

Cellulose crystallinity has long been thought to play an important role in enzymatic hydrolysis [55]. The concept that cellulose structure is divided into two regions, an amorphous region that is easy for enzymes to digest and a crystalline region that is difficult to digest, is extremely appealing. This provides a ready explanation of observed cellulose digestion kinetics, where enzymes more rapidly digest the 'easy and presumed amorphous' material before more slowly digesting the more difficult crystalline cellulose. However, the interpretation of data on cellulose hydrolysis by enzymes in terms of the CI of the substrate is not straightforward, for several reasons.

First, the reported changes in CI after enzymatic hydrolysis do not show a clear trend. Even though many studies have produced evidence to support the idea that CI increases during enzymatic hydrolysis [18,56,57], the reported increase has often been small. Chen and coworkers [56] found only a $2.6 \%$ increase in CI after $18 \%$ conversion of bacterial cellulose. Wang and co-workers [57] found only a $2.0 \%$ increase in CI after 6 days of crude cellulase hydrolysis of cotton fibers. This suggests a slightly preferential hydrolysis of amorphous cellulose. In one case, it was reported that there was no discernible difference in the CI of hemp fibers [58] and unbleached kraft pulp [59], after partial enzymatic digestion. Thus, it is unclear from these data if there is a preferential digestion of the amorphous cellulose component. By contrast, celluloses that are made highly amorphous by dissolution in a cellulose solvent followed by regeneration have been shown to have extremely high hydrolysis rates, with initial rates approximately three times higher than those of untreated celluloses[60]. 
A second problem is the coupling of crystallinity with other cellulose properties. During any chemical/mechanical/biological treatment, the CI of cellulose can be changed and then correlated with the measured digestibility. However, differences in observed enzyme hydrolysis kinetics may be governed by other characteristics such as available surface area, degree of polymerization and particle size. For example, the increased digestibility for finely ground sawdust particles may be due to both decreased CI and increased surface area [61]. Decoupling CI from changes in other properties has proven extremely difficult [62].

A third problem is that the structure of cellulose is actually more complicated than the two-phase model (crystalline and amorphous) indicates. As mentioned, Larsson and co-workers [32] reported that the amount of paracrystalline cellulose $(33.1 \%)$ is almost identical to the amount of crystalline structure (31.8\%) in cotton cellulose. The existence of this transition region between crystalline and amorphous structures makes interpretation even more difficult. In addition, structural and enzymatic studies [63-66] on various celluloses have suggested that larger scale structures in celluloses may significantly affect the accessibility of cellulose to enzymes. For example, if an amorphous region is buried in the interior of a particle that is packed sufficiently tightly by neighboring crystallites to be essentially impenetrable to the enzymes, reaction with the amorphous component will probably be impeded.

A fourth problem is related to the measurement technique, especially for XRD measurements. From the literature survey, we found that a significant number of references for the XRD methods used spectra of very poor quality. To evaluate small changes in $\mathrm{CI}$, it is crucial to have XRD with a high signal to noise level, as exemplified by the spectra shown here. None of the figures in this paper have been processed using a smoothing function; all show unprocessed raw data.

Finally, there are large discrepancies in the amorphous contents measured by different groups (between about 8 and $40 \%$ for Avicel PH-101, depending on method) and the thresholds at which cellulose digestion rates are reported to slow down. Andersen and co-workers [67] reported that when digested with a commercial enzyme mixture, Avicel PH-101 was hydrolyzed up to $7 \%$ in 24 hours. Most of this hydrolysis (5\%) was accomplished in the first 5 hours of the digestion, with the hydrolysis rate decreasing sharply thereafter. Using single endoglucanases and cellobiohydrolases for the hydrolysis of Avicel PH-101, rather than complete systems, Szijártó and coworkers [68] found that each digestion curve showed a sharp decrease in rate at a point well below $2 \%$ conversion. Even earlier, Tomme and co-workers [69], studied the relationship between the hydrolytic capabilities of dif- ferent cellulases with amorphous and crystalline Avicel. From their results on the crystalline substrate it can be estimated that cellulose conversion was $<1.3 \%$ using an intact cellobiohydrolase (CBH) I from Trichoderma reesei and $<0.2 \%$ for its proteolytically cleaved catalytic domain alone (both forms of the enzyme were used at a moderate but realistic loading ratio of $15 \mathrm{mg}$ enzyme per gram of cellulose) during the three hour assay. In all cases, it appears that the amount of rapidly digested cellulose is substantially less than the amorphous cellulose content measured by any of the methods.

\section{Conclusions}

It is clear that the most popular method for estimating cellulose $\mathrm{CI}$, the XRD height method, produces values that are significantly higher than the other methods. Literature data for Avicel PH-101 and data from our measurement of eight other celluloses using four methods support this idea. The other methods studied in this work rank the celluloses in roughly the same order as the XRD height method; however, the CI values from the height method are significantly higher. It seems likely that the reason for the popularity of the XRD height method is that it is the easiest to use. It should be remembered that Segal and coworkers only intended this method to be used as a 'time-saving empirical measure of relative crystallinity' [19]. We suggest that the other XRD and NMR methods presented here, which consider the contributions from both amorphous and crystalline cellulose to the whole of the XRD or NMR spectrum, provide a more accurate measure of the crystallinity of cellulose samples.

Although celluloses having a high amorphous content are usually more easily digested by enzymes, it is unclear based on the studies published in the literature that CI provides a clear indication of the digestibility of a cellulose sample. Accessibility of plant cell wall cellulose microfibrils to the various exo- and endocellulases necessary for cellulose hydrolysis appears to be the most important factor in determining hydrolysis rate. Enzyme accessibility should be affected by crystallinity, but it is also known to be affected by the lignin and hemicellulose contents/distribution, the particle size, and the porosity of the native cell wall sample. Consequently, $\mathrm{CI}$ is just one of several parameters that should be considered in assessing the likely enzymatic hydrolysis rate of cellulose in a biomass sample. In addition, if the enzymes work ablatively on cellulose microfibril surfaces, consuming the less ordered surface layers of cellulose, then internal ordered cellulose chains will become surface chains with decreased order, so that conversion of 'amorphous cellulose' results in production of more 'amorphous cellulose' and a further decrease in cellulose CI.

Enzymatic cellulose hydrolysis is a complex process, and $\mathrm{CI}$ alone may not adequately explain differences in 
Table 2: $\mathrm{Cl}$ of celluloses determined by four different methods by the authors.

\begin{tabular}{lllll}
\hline Cellulose tested & \multicolumn{2}{l}{ XRD method } & & NMR method \\
\cline { 2 - 4 } & Peak height & Peak deconvolution & Amorphous subtraction & C4 peak separation \\
\hline BMCC & 95.2 & 73.1 & 82.4 & 73.8 \\
\hline Avicel PH-101* & $91.7 \pm 1.5$ & $60.6 \pm 1.0$ & $77.7 \pm 1.9$ & $56.7 \pm 2.2$ \\
\hline SigmaCell 50 & 91.2 & 61.3 & 79.4 & 52.6 \\
\hline SigmaCell 20 & 84.8 & 64.2 & 67.0 & 49.1 \\
\hline JT Baker cellulose & 85.5 & 61.5 & 69.1 & 48.6 \\
\hline Fluka cellulose & 82.9 & 52.9 & 61.6 & 43.9 \\
\hline SolkaFloc cellulose & 78.3 & 56.8 & 57.2 & 41.5 \\
\hline Sigma a-cellulose & 78.0 & 55.9 & 54.4 & \\
\hline BMCC, bas. & & & & \\
\hline
\end{tabular}

BMCC, bacterial microcrystalline cellulose.

Values are means.

* For Avicel PH-101 the standard deviation from three measurements is given.

observed hydrolysis rates. Given the method dependency for determining the CI values of cellulose preparations likely to be used in assessing the performance of cellulases, and the complex nature of the interaction of cellulases with amorphous and crystalline celluloses, we caution against trying to correlate relatively small changes in $\mathrm{CI}$ with changes in cellulose digestibility. Similarly, it is difficult to interpret enzymatic cellulose digestion rate studies unless the digestion is taken near to completion, as it is unclear whether or not the enzyme has been acting on the more easily converted amorphous component. If the digestion is taken to completion, or at least to a level well beyond the amorphous content, uncertainty about the performance of the enzyme is reduced.

\section{Competing interests}

The authors declare that they have no competing interests.

\section{Authors' contributions}

JP obtained X-ray powder diffraction spectra on the various cellulose samples, calculated $\mathrm{Cl}$ values from all NMR and XRD spectra by the various techniques, studied and analyzed the literature measurements of $\mathrm{Cl}$ and drafted the manuscript. JOB contributed literature information on the relationship between enzymatic digestibility and $\mathrm{Cl}$ and helped draft the manuscript. MEH helped draft the manuscript. PAP helped draft the manuscript and provided input on the measurement of $\mathrm{Cl}$ by XRD. DKJ contributed to the original conception of the study, advised on the design and progress of the experimentation and helped draft the manuscript. All authors critically revised the draft and approved the final manuscript.

\section{Acknowledgements}

This work was funded by the US Department of Energy through the office of the Biomass Program.

\section{Author Details}

'Biosciences Center, National Renewable Energy Laboratory, 1617 Cole Blvd, Golden, CO 80401, USA, 2 National Center for Photovoltaics, National

Renewable Energy Laboratory, 1617 Cole Blvd, Golden, CO 80401, USA and ${ }^{3}$ Department of Forest Biomaterials, North Carolina State University, Raleigh, NC 27695, USA

Received: 15 May 2009 Accepted: 24 May 2010

Published: 24 May 2010

\section{References}

1. Hayashi J, Sufoka A, Ohkita J, Watanabe S: Confirmation of existence of cellulose III(I), III(II), IV(I), and IV(II) by x-ray method. J Polym Sci Polym Lett 1975, 13:23-27.

2. Gardiner ES, Sarko A: Packing analysis of carbohydrates and polysaccharides. 16. The crystal-structures of cellulose $\mathrm{IV}_{1}$ and cellulose IV ${ }_{11}$. Can J Chem 1985, 63:173-180.

3. Pérez S, Mazeau K: Conformations, structures, and morphologies of celluloses. In Polysaccharides: Structural diversity and functional versatility 2nd edition. Edited by: S. Dumitriu. Marcel Dekker; 2005.

4. O'Sullivan A: Cellulose: the structure slowly unravel. Cellulose 1997, 4:173-207.

5. Zugenmaier P: Cellulose. In Crystalline Cellulose and Cellulose Derivatives: Characterization and structures. Springer Series in Wood Science Berlin, Heidelberg: Springer-Verlag; 2008:101-174.

6. Wilkie JS: Carl Nägeli and the fine structure of living matter. Nature 1961, 190:1145-1150.

7. Meyer KH, Misch L: Positions des atomes dans le nouveau modèle spatial de la cellulose. Helv Chim Acta 1937, 20:232-244.

8. Atalla RH, Vanderhart DL: Native cellulose: a composite of two distinct crystalline forms. Science 1984, 223:283-285. 
9. Nisizawa K: Mode of action of cellulases. J Ferment Technol 1973, 51:267-304.

10. Åkerholm M, Hinterstoisser B, Salmén L: Characterization of the crystalline structure of cellulose using static and dynamic FT-IR spectroscopy. Carbohydr Res 2004, 339:569-578.

11. Evans $R$, Newman RH, Roick UC: Changes in cellulose crystallinity during kraft pulping. Comparison of infrared, $\mathrm{x}$-ray diffraction and solid state NMR results. Holzforschung 1995, 49:498-504.

12. Kataoka Y, Kondo T: FT-IR microscopic analysis of changing cellulose crystalline structure during wood cell wall formation. Macromolecules 1998, 31:760-764

13. Schenzel K, Fischer S, Brendler E: New method for determining the degree of cellulose I crystallinity by means of FT Raman spectroscopy. Cellulose 2005, 12:223-231.

14. He J, Cui S, Wang S-Y: Preparation and crystalline analysis of high-grade bamboo dissolving pulp for cellulose acetate. J Appl Polym Sci 2008, 107:1029-1038.

15. Thygesen A, Oddershede J, Lilholt H, Thomsen AB, Ståhl K: On the determination of crystallinity and cellulose content in plant fibres. Cellulose 2005, 12:563-576.

16. Helbert W, Chanzy H, Husum TL, Schulein M, Ernst S: Fluorescent cellulose microfibrils as substrate for the detection of cellulase activity. Biomacromolecules 2003, 4:481-487.

17. Wang Y, Zhao YL, Deng YL: Effect of enzymatic treatment on cotton fiber dissolution in $\mathrm{NaOH} / \mathrm{urea}$ solution at cold temperature. Carbohydr Polym 2008, 72:178-184.

18. Cao Y, Tan H: Study on crystal structures of enzyme-hydrolyzed cellulosic materials by X-ray diffraction. Enzyme Microb Tech 2005, 36:314-317.

19. Segal L, Creely JJ, Martin AE Jr, Conrad CM: An empirical method for estimating the degree of crystallinity of native cellulose using the $x$-ray diffractometer. Tex Res J 1962, 29:786-794

20. Hult LE, Iversen T, Sugiyama J: Characterization of the supramolecular structure of cellulose in wood pulp fibres. Cellulose 2003, 10:103-110.

21. Garvey CJ, Parker IH, Simon GP: On the interpretation of X-ray diffraction powder patterns in terms of the nanostructure of cellulose I fibres. Macromol Chem Phys 2005, 206:1568-1575.

22. Smith SO, Kustanovich I, Wu X, Peersen OB: Variable-amplitude crosspolarization MAS NMR. J Magn Reson 1994, 104:334-339.

23. Newman RH: Homogeneity in cellulose crystallinity between samples of Pinus radiata wood. Holzforschung 2004, 58:91-96.

24. Space-group symmetry: International Tables for Crystallography. Volume A. 5th edition. Edited by: Hahn T. Dordrecht: Kluwer Academic Publishing; 2002.

25. Klug H, Alexander L: X-ray Diffraction Procedures for Polycrystalline and Amorphous Materials. 2nd edition. New York: John Wiley \& Sons; 1974.

26. Jenkins R, Snyder R: Introduction to $x$-ray powder diffractometry. In Chemical Analysis Volume 138. New York: John Wiley \& Sons; 1996.

27. Teeäär R, Serimaa R, Paakkarl T: Crystallinity of cellulose, as determined by CP/MAS NMR and XRD methods. Polym Bull 1987, 17:231-237.

28. Gümüskaya E, Usta M, Kirci H: The effects of various pulping conditions on crystalline structure of cellulose in cotton linters. Polym Degrad Stabil 2003, 81:559-564.

29. Ruland W: X-ray determination of crystallinity and diffuse disorder scattering. Acta Cryst 1961, 14:1180-1185.

30. Atalla RH, Vanderhart DL: The role of solid state 13C NMR spectroscopy in studies of the nature of native celluloses. Solid State Nucl Magn Reson 1999, 15:1-19

31. Mansfield SD, Meder R: Cellulose hydrolysis - the role of monocomponent cellulases in crystalline cellulose degradation. Cellulose 2003, 10:159-169.

32. Larsson PT, Wickholm $\mathrm{K}$, Iversen T: A CP/MAS C-13 NMR investigation of molecular ordering in celluloses. Carbohydr Res 1997, 302:19-25.

33. Andersson S, Wikberg H, Pesonen E, Maunu S, Serimaa R: Studies of crystallinity of Scots pine and Norway spruce cellulose. Trees 2004, 18:346-353.

34. Liitiä T, Maunu SL, Hortling B: Solid state NMR studies on cellulose crystallinity in fines and bulk fibres separated from refined kraft pulp. Holzforschung 2000, 54:618-624.

35. Liitiä T, Maunu SL, Hortling B, Tamminen T, Pekkala O, Varhimo A: Cellulose crystallinity and ordering of hemicelluloses in pine and birch pulps as revealed by solid-state NMR spectroscopic methods. Cellulose 2003, 10:307-316.

36. Zhao H, Kwak JH, Wang Y, Franz JA, White JM, Holladay JE: Effects of crystallinity on dilute acid hydrolysis of cellulose by cellulose ballmilling study. Energy Fuels 2006, 20:807-811.

37. Pu Y, Ziemer C, Ragauskas AJ: CP/MAS 13C NMR analysis of cellulase treated bleached softwood kraft pulp. Carbohydr Res 2006, 341:591-597.

38. Hult EL, Larsson PT, Iversen T: A comparative CP/MAS 13C-NMR study of cellulose structure in spruce wood and kraft pulp. Cellulose 2000, 7:35-55.

39. Hori R, Wada M: The thermal expansion of cellulose II and III ${ }_{\|}$crystals. Cellulose 2006, 13:281-290

40. Rowe RC, McKillop AG, Bray D: The effect of batch and source variation on the crystallinity of microcrystalline cellulose. Int J Pharm 1994, 101:169-172.

41. Landin M, Martinezpacheco R, Gomezamoza UL, Souto C, Concheiro A, Rowe RC: Effect of country of origin on the properties of microcrystalline cellulose. Int J Pharm 1993, 91:123-131.

42. Castellan A, Ruggiero R, Frollini E, Ramos LA, Chirat C: Studies on fluorescence of cellulosics. Holzforschung 2007, 61:504-508.

43. Dadi A, Schall C, Varanasi S: Mitigation of cellulose recalcitrance to enzymatic hydrolysis by ionic liquid pretreatment. Appl Biochem Biotechnol 2007, 136-140:407-421.

44. El-Sakhawy M, Hassan ML: Physical and mechanical properties of microcrystalline cellulose prepared from agricultural residues. Carbohydr Polym 2007, 67:1-10

45. Vyas S, Pradhan SD, Pavaskar NR, Lachke A: Differential thermal and thermogravimetric analyses of bound water content in cellulosic substrates and its significance during cellulose hydrolysis by alkaline active fungal cellulases. App/ Biochem Biotechnol 2004, 118:177-188.

46. Granja PL, Pouysegu L, Petraud M, De Jeso B, Baquey C, Barbosa MA: Cellulose phosphates as biomaterials. I. Synthesis and characterization of highly phosphorylated cellulose gels. J Appl Polym Sci 2001 82:3341-3353.

47. Heng PWS, Liew CV, Soh JLP: Pre-formulation studies on moisture absorption in microcrystalline cellulose using differential thermogravimetric analysis. Chemical \& Pharmaceutical Bulletin 2004, 52:384-390.

48. Marson GA, El Seoud OA: Cellulose dissolution in lithium chloride/N,Ndimethylacetamide solvent system: relevance of kinetics of decrystallization to cellulose derivatization under homogeneous solution conditions. J Polym Sci Polym Chem 1999, 37:3738-3744.

49. Gama FM, Mota M: Enzymatic hydrolysis of cellulose. 1. Relationship between kinetics and physico-chemical parameters. Biocatal Biotransform 1997, 15:221-236

50. Hsu JC, Penner MH: Preparation and utilization of cellulose substrates regenerated after treatment with hydrochloric acid. J Agr Food Chem 1991, 39:1444-1447.

51. Zhang S, Winter WT, Stipanovic AJ: Water-activated cellulose-based electrorheological fluids. Cellulose 2005, 12:135-144.

52. Jumaa M, El Saleh F, Hassan I, Muller BW, Kleinebudde P: Influence of cellulose type on the properties of extruded pellets. Part I. Physicochemical characterisation of the cellulose types after homogenisation. Colloid Polym Sci 2000, 278:597-607.

53. Nakai Y, Fukuoka E, Nakajima S, Hasegawa J: Crystallinity and physical characteristics of microcrystalline cellulose. Chem Pharmaceut Bull 1977, 25:96-101.

54. Ek R, Gustafsson C, Nutt A, Iversen T, Nyström C: Cellulose powder from Cladophora sp. algae. J Mol Recogn 1998, 11:263-265.

55. Fan LT, Lee YH, Beardmore DH: Mechanism of the enzymatic hydrolysis of cellulose: Effect of major structural features of cellulose on enzymatic hydrolysis. Biotechnol Bioeng 1980, 23:177-199.

56. Chen Y, Stipanovic AJ, Winter WT, Wilson DB, Kim YJ: Effect of digestion by pure cellulases on crystallinity and average chain length for bacterial and microcrystalline celluloses. Cellulose 2007, 14:283-293.

57. Wang L, Zhang Y, Gao P, Shi D, Liu H, Gao H: Changes in the structural properties and rate of hydrolysis of cotton fibers during extended enzymatic hydrolysis. Biotechnol Bioeng 2006, 93:443-456.

58. Buschle-Diller G, Fanter C, Loth F: Structural changes in hemp fibers as a result of enzymatic hydrolysis with mixed enzyme systems. Text Res $\rfloor$ 1999, 69:244-251. 
59. Mansfield SD, de Jong E, Stephens RS, Saddler JN: Physical characterization of enzymatically modified kraft pulp fibers. J Biotechnol 1997, 57:205-216.

60. Zhang YHP, Cui JB, Lynd LR, Kuang LR: A transition from cellulose swelling to cellulose dissolution by o-phosphoric acid: Evidence from enzymatic hydrolysis and supramolecular structure. Biomacromolecules 2006, 7:644-648.

61. Dasari R, Berson R: The effect of particle size on hydrolysis reaction rates and rheological properties in cellulosic slurries. Appl Biochem Biotechnol 2007, 137:289-299.

62. Zhang YHP, Lynd LR: Toward an aggregated understanding of enzymatic hydrolysis of cellulose: Noncomplexed cellulase systems. Biotechnol Bioeng 2004, 88:797-824.

63. Peters $L E$, Walker $L P$, Wilson $D B$, Irwin $D C$ : The impact of initial particlesize on the fragmentation of cellulose by the cellulases of Thermomonospora-fusca. Bioresource Technol 1991, 35:313-319.

64. Walker LP, Wilson DB, Irwin DC, McQuire C, Price M: Fragmentation of cellulose by the major Thermomonospora-fusca Cellulases, Trichoderma reesei CBHI, and their mixtures. Biotechnol Bioeng 1992, 40:1019-1026.

65. Dong XM, Revol JF, Gray DG: Effect of microcrystallite preparation conditions on the formation of colloid crystals of cellulose. Cellulose 1998, 5:19-32.

66. Fleming K, Gray DG, Matthews S: Cellulose crystallites. Chem Eur 2001, 7:1831-1835

67. Andersen N, Johansen K, Michelsen M, Stenby E, Krogh K, Olsson M: Hydrolysis of cellulose using mono-component enzymes shows synergy during hydrolysis of phosphoric acid swollen cellulose (PASC), but competition on Avicel. Enzyme Microb Technol 2008, 42:362-370.

68. Szijártó N, Siika-aho M, Tenkanen M, Alapuranen M, Vehmaanpera J, Reczeya K, Viikari L: Hydrolysis of amorphous and crystalline cellulose by heterologously produced cellulases of Melanocarpus albomyces. J Biotechnol 2008, 136:140-147.

69. Tomme P, Vantilbeurgh H, Pettersson G, Vandamme J, Vandekerckhove J, Knowles J, Teeri T, Claeyssens M: Studies of the cellulolytic system of Trichoderma reesei QM 9414 - Analysis of domain function in two cellobiohydrolases by limited proteolysis. Eur J Biochem 1988, 170:575-581.

70. Schroeder LR, Gentile VM, Atalla RH: Nondegradative preparation of amorphous cellulose. J Wood Chem Tech 1986, 6:1-14.

doi: 10.1186/1754-6834-3-10

Cite this article as: Park et al., Cellulose crystallinity index: measurement techniques and their impact on interpreting cellulase performance Biotechnology for Biofuels 2010, 3:10

\section{Submit your next manuscript to BioMed Central} and take full advantage of:

- Convenient online submission

- Thorough peer review

- No space constraints or color figure charges

- Immediate publication on acceptance

- Inclusion in PubMed, CAS, Scopus and Google Scholar

- Research which is freely available for redistribution

Submit your manuscript at www.biomedcentral.com/submit
C Biomed Central 